(с) А.П. Лущикова ${ }^{1 *}$, А.И. Чемшит ${ }^{2}$

'Первый Московский государственный медицинский университет имени И.М. Сеченова (Сеченовский Университет), Москва, Россия

${ }^{2}$ Национальный исследовательский ядерный университет «МИФИ», Москва, Россия

В начале XX в. весь мир находился в поисках направлений применения радиоактивных веществ, в частности радия. Радий стали использовать для лечения онкологии, однако никто не знал грани между чрезмерной и недостаточной поглощенной дозой облучения. Родоначальником радиобиологии можно считать Льюиса Гарольда Грея, который смог определить поглощенную дозу радиации, единица измерения которой в системе СИ названа в его честь. Но именно Эдит Квимби занялась поиском той самой терапевтически эффективной поглощенной дозы. Ее задачей было рассчитать минимальную дозировку радиоактивности для каждого пациента. Ею были написаны 75 статей, выпущены книги, которые стали основой современных понятий биофизики и настольными книгами последующих поколений радиологов. Она стала первой женщиной и первым физиком, который стал президентом Американского Общества Радия, организацией, которая занимается изучением и лечением онкологии. В свое время Артур Комптон сказал о необходимости внедрять и применять физику в медицине, а Квимби в своей благодарственной речи высказала необходимость создания общества медицинских физиков, и в 1958 г. было создано Американское Общество Медицинских Физиков. Эдит Квимби была и остается знаковой фигурой в истории развития медицинской физики.

КЛЮЧЕВЫЕ СЛОВА: Эдит Хинкли Квимби; медицинская физика; радиобиология; лучевая терапия; онкология щитовидной железы; эндокринология; радиология; история медицины.

\title{
ANNIVERSARY OF EDITH HINKLEY QUIMBY
}

\author{
(c) Anna P. Lushchikova ${ }^{1 *}$, Anastasia I. Chemshit ${ }^{2}$
}

'I.M. Sechenov First Moscow State Medical University (Sechenov University), Moscow, Russia

${ }^{2}$ National Research Nuclear University MEPhl (Moscow Engineering Physics Institute), Moscow, Russia

At the beginning of the 20th century, the whole world was searching for radioactive substances application, in particular radium. Radium can be used to treat oncology, but no one knew the verge of overdosing and underdosing. The founder of radiobiology can be considered Lewis Gray, who introduced unit for absorbed dose of radiation [1]. It was Edith Quimby who started looking for that therapeutically effective absorbed dose. It's to calculate the minimum effective dose of activity for each patient. She has written 75 articles, published books that have become used concepts in biophysics, and handbooks of modern editions of radiologists. She became the first woman and the first physicist to become president of the American Radium Society, an organization dedicated to the study and treatment of cancer. At one time, Arthur Compton spoke about the need to introduce and apply physics in medicine, and Quimby, in her acceptance speech, outlined the need for an organization of medical physicists, and in 1958, owing to her, the American Society of Medical Physicists was created. Edith Quimby was and remains an iconic figure in the history of the development of medical physics.

KEYWORDS: Edith H. Quimby; medical physics; radiobiology; radiation therapy; thyroid carcinoma; endocrinology; history of medicine.

\section{ЖИЗНЬ И ПРОФЕССИЯ}

Эдит Хинкли Квимби (рис.) родилась 10 июля 1891 г. в семье Артура и Нарриет Хинкли в Рокфорде, впоследствии семья переехала в Айдахо, где Квимби и закончила среднюю школу.

Эдит Хинкли росла очень любознательным ребенком и благодаря наставлениям отца и учителей научилась находить ответы на все интересующие вопросы в книгах. После окончания школы девушка получила возможность обучаться в колледже Уитмена Уолла, штат Вашингтон, где стала первой женщиной, окончившей курс физики и математики.

После колледжа работала преподавателем естественных наук в Ниссе, штат Орегон. В 1916 г. окончила Калифорнийский университет и получила степень магистра по физике, а также вышла замуж за Ширли Леона Квимби [2].

Ее муж работал преподавателем в Антиохийском институте, однако после зачисления в военно-морской флот Эдит заняла его место. В 1919 г. стала преподавателем в Колумбийском университете и получила степень кандидата физических наук. 


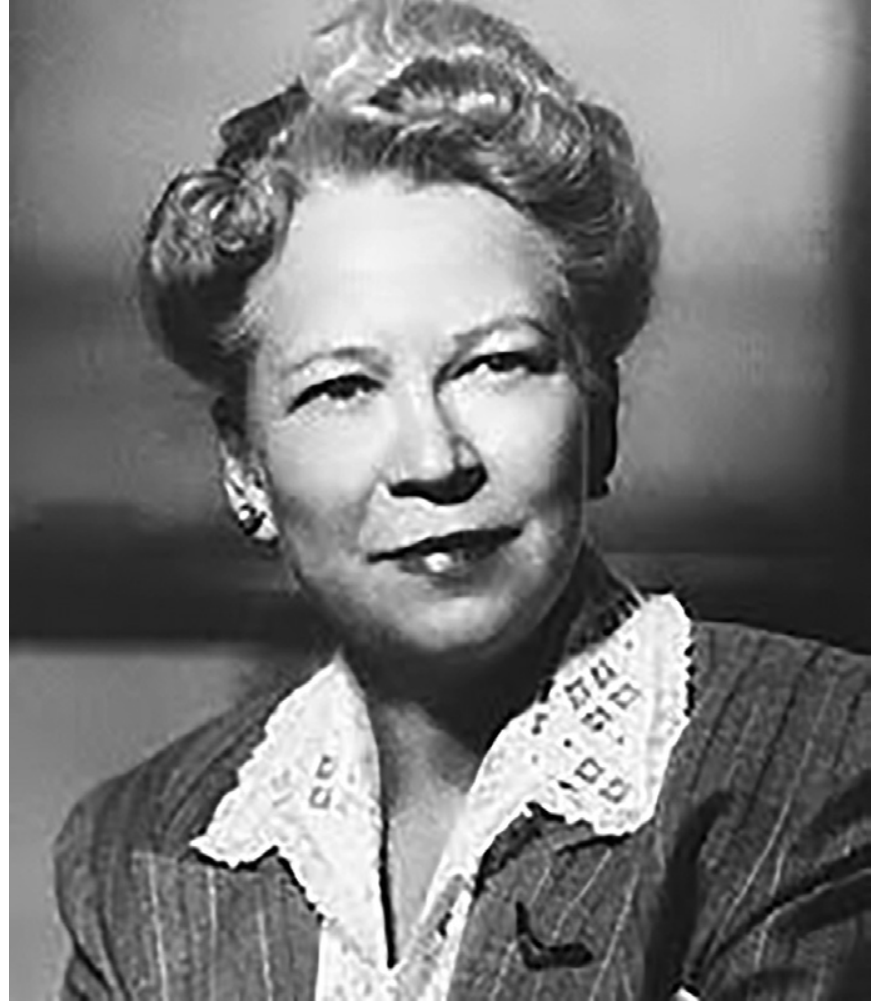

Рисунок. Эдит Хинкли Квимби.

Материальное положение семьи было тяжелым, и для того, чтобы продолжать жить в Нью-Йорке, девушка вынуждена была искать работу, помимо преподавания в Колумбийском университете. В это время в Мемориальной больнице физик Джоаккино Файлла занимался исследованиями применения радиации в медицине и искал себе помощника. С его слов, Файлла никогда не думал, что его ассистентом может стать юная девушка, однако готов был дать Эдит Квимби шанс с испытательным сроком в 6 мес. Их сотрудничество в дальнейшем продлилось более 40 лет [3, 4].

В то время не существовало общепринятых методов лечения, но уже тогда радий активно использовался в лечении онкологии. Радийсодержащие иглы апплицировались к опухолям в хаотичном порядке, без какой-либо уверенности в том, что опухоль получит достаточное радиационное воздействие. Квимби была первой, кто определил распределение поглощенной дозы излучения в тканях, в зависимости от порядка аппликации игл. Методы, описанные ей в 1932 г., по выбору наиболее эффективной позиции радиевых игл послужили основой для формирования системы Паркера-Патерсона (она же Манчестерская система, предусматривает получение однородной дозы в плоскости и объеме), а также широко применялись в США до середины восьмидесятых годов, до активного развития компьютерных технологий. В это же время она заметила, что различные количества бета- и гамма-лучей вызывают один и тот же биологический эффект - эритему кожи. Основываясь на этом, она сформировала концепцию относительной биологической эффективности радиации, использование которой существует и по сей день [5].

В 1940 г. она была награждена Медалью Дженуэй от Американского Радиевого Общества, а в 1941 г. получила Золотую медаль от Радиологического общества
Северной Америки. Жизнь Эдит Квимби была неразрывно связана не только с физикой, но и с медициной. С 1941 г. была доцентом кафедры радиологии медицинского колледжа Корнельского университета, а с 1942 по 1954 гг. - доцентом кафедры радиологической физики Колледжа врачей и хирургов Колумбийского университета, где работала с искусственными радиоизотопами. Исследования основывались на применении радиоактивного натрия йодида ля диагностики и лечения рака щитовидной железы и опухолей головного мозга. Состояла в Американском физическом обществе и была президентом Американского общества радия, была членом Консультативного комитета по медицинскому использованию изотопов, Комиссии по атомной энергии. С 1954 г. посвятила себя преподаванию в Колумбийском университете. В 1960 г. стала заслуженным профессором радиологии [6].

\section{РАДИОЙОДТЕРАПИЯ ТИРЕОТОКСИКОЗА}

Свой вклад в эндокринологию Квимби внесла работой «О поздних осложнениях лучевой терапии у пациентов с гипертиреозом».

Статья была опубликована в 1949 г. В ней она и ее команда ответили на вопрос о безопасности проведения радионуклидной терапии гипертиреоза с применением радиоактивного йода. Опрос проводился среди 70 рентгенологов и 31 эндокринолога. Респонденты должны были ответить на ряд вопросов.

1. Наблюдали ли вы возникновение онкологии щитовидной железы после радионуклидной терапии гипертиреоза йодом? Если да, определялись ли в щитовидной железе узлы?

2. Наблюдали ли вы развитие онкологии в окружающих тканях после радионуклидной терапии гипертиреоза йодом?

3. Видели ли вы возникновение онкологических заболеваний в непораженной щитовидной железе, при воздействии излучения на эту зону в связи с другим заболеванием?

4. Видели ли вы развитие рака щитовидной железы у пациентов, которые подвергались лечению гипертиреоза не лучевыми методами?

Если ответом на один из вопросов являлось «Да», то специалист должен был прикрепить историю болезни данного пациента.

Всего 71 специалист ответили «Нет» на весь перечень вопросов, еще 4 посчитали себя некомпетентными в данной теме.

На первый вопрос 10 докторов ответили «Да» и прислали соответствующие истории болезней. Обобщая их, можно сказать, что излучение никак не повлияло на малигнизацию тканей у кого-либо из этих пациентов. Стоит отметить, что в то время технология наработки йода отличалась от современной, в состав могли входить примеси радиоактивных веществ, что могло сказаться на образовании неоплазий.

Отвечая на второй вопрос, 8 рентгенологов утверждали, что они видели развитие рака в окружающих тканях - коже шеи - после лучевой терапии гипертиреоза. Также были сведения о двух случаях рака гортани, одном случае рака пищевода и одном случае рака 
трахеи. Пациенты с раком пищевода и трахеи, женщины 34 и 28 лет, получили довольно большую дозу радиации. Стоит отметить, что у обеих позже были выявлены обширные телеангиэктазии в области облученной зоны.

Отвечая на третий вопрос, никто не дал сведений о зарегистрированных случаях развития рака в непораженной щитовидной железе.

Что касается четвертого вопроса, 9 специалистов заявили об увиденных случаях развития рака щитовидной железы на фоне лечения гипертиреоза не лучевой терапией.

По результатам данного опроса, можно было сделать вывод, что если осложнения и существуют, то встречаются довольно редко. Исходя из этого, авторы сделали вывод, что польза от лучевой терапии радиоактивным йодом при гипертиреозе превосходила риски дальнейшей малигнизации железы и близлежащих тканей [7]. Эти исследования сделали Эдит Квимби пионером в области ядерной медицины и медицинской физики. Стоит отметить, что на сегодняшний день технология радиойодтерапии проводится безопасно. Многолетний опыт позволил минимизировать радиационное воздействие, в том числе это заслуга Квимби, которая дала первую математическую модель расчета терапевтической активности. Сегодня последователи применяют современные методы моделирования распространения элементарных частиц и умеют прогнозировать достижения эффекта лечения на предтерапевтическом этапе.

Помимо этого, будучи плодовитым писателем, она сделала ряд публикаций по различным аспектам медицинского применения рентгеновских лучей и радиоактивных изотопов. Эдит Квимби также была соавтором широко известной книги под названием “Физические основы радиологии". По мере того, как радиационная физика и биофизика становились все более важными и актуальными, возникла потребность в профессионально подготовленных специалистах во всех отраслях этой области.

В Колумбийском университете доктор Квимби оказала помощь в разработке двух программ повышения квалификации. Одна из них подразумевает получение степени магистра в радиологической физике, а другая - докторскую степень в области биофизики. И то и другое предполагает сотрудничество значительной группы профессорско-преподавательского состава, что способствовало формированию междисциплинарной команды специалистов. Несмотря на свой уход на пенсию, доктор Квимби все еще активно преподавала в обеих этих программах [8]. Она всегда интересовалась профессиональными обществами и их деятельностью. Эдит Квимби была приглашенным экспертом Американского совета радиологии с 1934 г., членом Национального комитета по радиационной защите и измерениям с 1937 г.

Она много путешествовала по Европе и Южной Америке, принимала участие во многих международных и межамериканских конгрессах по радиологии, также являлась почетным членом нескольких латиноамериканских радиологических организаций.

Ее почести и награды были многочисленными. Эдит имеет две почетные докторские степени, одну в Уитмен-колледже и одну в Университете Ратгерса.

\section{ЗАКЛЮЧЕНИЕ}

О себе Эдит Квимби говорила: «Моя жизнь была счастливой и интересной. Моя профессиональная карьера началась с области, которая тогда была полна захватывающих проблем и которая со временем стала только увлекательнее. У меня всегда было хорошее здоровье и способность работать не покладая рук. Я благодарна за поддержку и помощь всем, кто был опорой и помогал мне достичь такого успеха. Прежде всего, я глубоко обязана доктору Джоаккино Файлле, который заинтересовал меня этой сферой и всегда был рядом, критиковал и подсказывал. Также хочу выразить благодарность своим коллегам, без которых не было бы и десятой части моей работы. Рядом всегда был любящий и понимающий муж, гордившейся любым моим достижением и готовый помочь реализовать каждую мою идею. Я с уверенностью могу сказать, что моя жизнь прошла прекрасно, я счастливый человек!» [4].

\section{ДОПОЛНИТЕЛЬНАЯ ИНФОРМАЦИЯ}

Конфликт интересов. Авторы декларируют отсутствие явных и потенциальных конфликтов интересов, связанных с публикацией настоящей статьи.

Участие авторов. Лущикова А.П. - ответственный за главу «Радиойодтерапия тиреотоксикоза», принимавший активное участие в написании главы «Жизнь и профессия», ответственный за внесение правок в статью; Чемшит А.И. - ответственный за главу «Заключение», принимавший активное участие в написании главы «Жизнь и профессия», консультант по вопросам медицинской физики.

\section{СПИСОК ЛИТЕРАТУРЫ | REFERENCES}

1. peoples.ru [интернет]. Льюис Харольд Грэй [доступ от 09.08.2020]. Доступно по: https://www.peoples.ru/science/physics/louis_harold_gray/

2. yourdictionary.com [Internet]. Edith H. Quimby Facts. Encyclopedia of World Biography. The Gale Group, Inc.; c2010 [updated 10 June, 2020; cited 9 August 9, 2020]. Available from: https://biography. yourdictionary.com/edith-h-quimby.

3. Edith Hinkley Quimby. J Nucl Med. 1965;6:383-385.

4. Susan Ware. Notable American women: A biographical dictionary. 5th edition. Cambridge, Mass; London: Belknap press, 2004. msu.edu [Internet]. Edith Quimby. The Health Physics Society.
1313 Dolley Madison Blvd., Suite 402 Mclean, Virginia 22101 [cited 09.08.2020]. Available from: https://ehs.msu.edu/lab-clinic/rad/ hist-figures/quimby.html.

6. CWP at UCLA [Internet]. Edith Hinkley Quimby. P. 1997-2001. [cited 2020 Aug 9]. Available from: http://cwp.library.ucla.edu/Phase2/ Quimby,_Edith_Hinkley@842345678.html

7. Quimby EH. Late radiation effects in roentgen therapy for hyperthyroidism. JAMA J Am Med Assoc. 1949;140(12):1046. doi: https://doi.org/10.1001/jama.1949.02900470050018

8. Edith Quimby. Phys Today. July 2017. doi: https://doi.org/10.1063/PT.6.6.20170710a 
ИНФОРМАЦИЯ ОБ АВТОРАХ [AUTHORS INFO]

*Лущикова Анна Павловна, студент [Anna P. Lushchikova, student]; адрес: Россия, 119991, Москва, ул. Трубецкая, д. 8, строение 2 [8-2 Trubetskaya street, 119991, Moscow, Russia]; ORCID: http://orcid.org/0000-0002-1343-5252; eLibrary SPIN: 9130-1274; e-mail: anlushch@gmail.com

Чемшит Анастасия Игоревна, студент [Anastasia I. Chemshit, student]; ORCID: http://orcid.org/0000-0002-2409-8706; e-mail:chemshit2000@mail.ru

\section{ЦИТИРОВАТЬ:}

Лущикова А.П., Чемшит А.И. К юбилею Эдит Хинкли Квимби // Клиническая и экспериментальная тиреоидология. 2021. - T. 17. — № 4. - С. 26-29. doi: https://doi.org/10.14341/ket12542

Рукопись получена: 22.07.2020. Одобрена к публикации: 29.11.2021.

\section{TO CITE THIS ARTICLE:}

Lushchikova AP, Chemshit Al. Anniversary of Edith Hinkley Quimby. Clinical and experimental thyroidology. 2021;17(4):26-29. doi: https://doi.org/10.14341/ket12542

Received: 22.07.2020. Accepted: 29.11.2021. 